\title{
METODE PENDIDIKAN INABAH DALAM MENGATASI \\ KENAKALAN REMAJA PONDOK PESANTREN SURYALAYA
}

\author{
Sahliah, Siti Hanipah \\ STIT Al-Ihsan Baleendah, IAILM Suryalaya \\ sahliah209@gmail.com, sitihanipah05@gmail.com
}

\begin{abstract}
Abstrack
This study aims to determine how the educational method of dealing with juvenile delinquency in handling juvenile delinquency using the Inabah rehabilitation method at Suryalaya Islamic Boarding School. The results of the study revealed that juvenile delinquency carried out by children built before Inabah is drunk, often skips school and is involved in the use of illegal drugs after completing education. Juvenile delinquency is divided into two, namely two-dimensional victims and five-dimensional victims with different levels of effect on each offender. Awareness or education methods consist of: bathing repentance, prayer fardlu and sunnah, dzikir jahar and dhikr khofi, talqin dzikir, fasting, other beneficial activities, and health checks and education skills. The way to overcome juvenile delinquency is through inabah education method in Suryalaya Islamic Boarding School consists of three stages, namely the rejection stage, the acceptance stage and the habituation stage. While the success of the Inabah method in overcoming juvenile delinquency is shown by the existence of medical awareness and spiritual awareness.
\end{abstract}

Keywords: Juvenile Delinquency, Inabah, Suryalaya

\begin{abstract}
Abstrak
Penelitian ini bertujuan untuk mengetahui bagaimana metode pendidikan mengatasi kenakalan remaja dalam menagani kenakalan remaja dengan menggunakan metode rehabilitasi Inabah di Pondok Pesantren Suryalaya. Hasil penelitian mengungkap bahwa kenakalan remaja yang dilakukan anak bina sebelum Inabah yaitu mabukmabukan, sering bolos sekolah dan terlibat penggunaan obat-obat terlarang setelah selesai mengikuti pendidikan sudah tidak dilakukan


hanya beberapa tindak kenakalan biasa seperti bolos sekolah dan tidur di kelas. kenakalan remaja terbagi dua yaitu korban dua dimensi dan korban lima dimensi dengan tingkat efek yang berbeda pada tiap pelaku. Metode penyadaran atau pendidikan terdiri dari: mandi taubat, shalat fardlu dan sunah, dzikir jahar dan dzikir khofi, talqin dzikir, puasa, kegiatan lainnya yang bermanfaat, dan pemeriksaan kesehatan dan pendidikan keterampilan. Cara mengatasi kenakalan remaja melalui metode pendidikan inabah di Pondok Pesantren Suryalaya terdiri dari tiga tahap yaitu tahap penolakan, tahap penerimaan dan tahap pembiasaan. Sedangkan keberhasilan metode Inabah dalam mengatasi kenakalan remaja ditunjukkan dengan adanya kesadaran medis dan kesadaran spiritual.

Kata kunci: Kenakalan Remaja, Inabah, Suryalaya 
Sahliah. Siti Hanipah | Metode Pendidikan Inabah...

\section{A. PENDAHULUAN}

Untuk mewujudkan manusia yang cerdas dan berkualitas pendidikan tidak hanya diorientasikan pada kecerdasan intelektualnya saja namun kecerdasan emosional pun harus dibimbing dan diarahkan agar menciptakan lulusan yang berwawasan luas dan memiliki moralitas yang tinggi. Pada masa sekarang dapat dilihat bahwa sudah banyak penyelewengan dikalangan peserta didik yang mulai merajalela. Seperti halnya budaya bolos sekolah, mencuri, bullying, terjangkit narkoba, berkata kasar, indisipliner di sekolah, berkelahi dan masih banyak lagi ragam kasus-kasus kenakalan dari yang ringan sampai yang bersifat kriminal sering kali terjadi. Hal ini menunjukan bahwa kecerdasan emosional dalam dunia pendidikan belum menjadi prioritas utama sesuai yang diharapkan.

Jika hal ini dikaitkan dengan agama, akan tampak bahwa agama belum teraktualisasikan sesuai ajaran-ajaran normatifnya. Religiusitas merupakan salah satu faktor utama dalam hidup dan kehidupan. Religiusitas yang tinggi ditandai dengan adanya keyakinan akan adanya Tuhan yang dimanivestasikan dalam proses individu mempelajari pengetahuan mengenai ajaran agama yang diyakininya dan prilaku yang sesuai dengan ajaran agamanya. Dalam agama Islam banyak ditekankan agar manusia senantiasa dapat mengendalikan hawa nafsunya dengan selalu bersabar dalam menghadapi masalah, senantiasa bekerja keras ketika ingin meraih sesuatu dan berserah diri ketika ikhtiar telah dilaksanakan semaksimal mungkin. Demikian pula kewajibankewajiban agama yang ditetapkan dalam rangka kebaikan dan kemaslahatan manusia. Dapat diumpamakan shalat, al-quran dan hadits banyak menyeru kaum muslim. Selain shalat adalah kewajiban yang menunjukkan kadar perbedaan seorang muslim dengan non muslim. Selain itu, shalat juga dapat mencegah dari perbuatan keji dan munkar. Religiusitas seseorang mestinya berimplikasi dalam segala kehidupannya, baik dalam belajar, bekerja, bergaul dan berusaha.

Beberapa faktor lain yang mempengaruhi tingkat religiusitas dan kecerdasan emosional remaja belum sesuai dengan norma-norma yang ada dan terjadinya perilaku tersebut dipengaruhi beberapa faktor yaitu kurangnya partisipasi orang tua dalam mendidik anak terutama dalam 
hal agama, lingkungan bermain yang kurang mendukung sehingga anak terpengaruh hal yang tidak sesuai dengan syariat agama, kurangnya perhatian siswa saat guru mengarahkan pada perilaku positif maupun meluruskan perilaku negatif peserta didik di lingkungan sekolah dan perkembangan tingkat usia remaja.

\section{B. METODE}

Berdasarkan permasalahan yang di teliti yaitu mengenai Pengaruh Religiusitas terhadap Kecerdasan Emosional Peserta Didik". Maka metode yang dianggap paling cocok adalah penelitian deskriptif.

Populsi dalam penelitian ini adalah Peserta didik yang ada di MA Serba Bakti Suryalaya berjumlah 305 orang dari mulai kelas $\mathrm{X}$ sampai dengan kelas XII, dan jumlah tersebut terbagi dalam 10 kelas dimana tiap angkatan dibagi kedalam 3 Kelas/Jurusan.

Teknik Sampling dalam penelitian ini akan menggunakan teknik "Purposive sampling" yaitu teknik sampling yang digunakan oleh peneliti jika peneliti mempunyai pertimbangan-pertimbangan tertentu didalam pengambilan sampel.

Dari jumlah populasi 305 diambil sampel secara utuh 10\% dari jumlah populasi yaitu 32 orang dari kelas XI IIK. Alasan peneliti memilih kelas tersebut karena peneliti memperhitungkan dari teknik penelitian yang akan dilakukan, diantaranya dengan menggunakan teknik angket yang memungkinkan dilakukan di kelas XI IIK yang dianggap sudah bisa mewakili kelas lainnya untuk dijadikan sampel.

Teknik pengumpulan Data dalam penelitian ini untuk memperoleh data yang valid, maka teknik pengumpulan data yang digunakan adalah Angket (Kuesioner), Wawancara dan Observasi.

\section{HASIL DAN PEMBAHASAN}

\section{Analisis Pengaruh Religiusitas}

Untuk mengolah pengaruh data pengaruh religiusitas terhadap kecerdasan emosional peserta didik di MA Serba Bakti 
Sahliah, Siti Hanipah I Metode Pendidikan Inabah...

Suryalaya, peneliti menyebarkan 32 angket kepada peserta didik sebagai sampel. Adapun hasil skoring data sebagai berikut:

Tabel 1

Rekapitulasi Nilai Angket Variabel X

\begin{tabular}{|c|c|c|c|c|c|c|c|c|c|c|c|c|c|c|c|c|}
\hline \multirow{3}{*}{$\begin{array}{l}\mathrm{N} \\
\mathrm{O}\end{array}$} & \multicolumn{15}{|c|}{ Item angket } & \multirow{3}{*}{$\begin{array}{c}\text { Jumla } \\
\mathrm{h}\end{array}$} \\
\hline & & & & & & & & & & 1 & 1 & & & 1 & 1 & \\
\hline & 1 & 2 & 3 & 4 & 5 & 6 & 7 & 8 & 9 & 0 & 1 & 2 & 3 & 4 & 5 & \\
\hline 1 & 4 & 4 & 4 & 1 & 4 & 1 & 4 & 4 & 4 & 4 & 4 & 4 & 4 & 1 & 4 & 51 \\
\hline 2 & 4 & 4 & 4 & 4 & 4 & 3 & 4 & 4 & 4 & 4 & 4 & 4 & 3 & 4 & 4 & 58 \\
\hline 3 & 4 & 2 & 4 & 4 & 4 & 3 & 4 & 4 & 4 & 4 & 4 & 4 & 4 & 1 & 4 & 54 \\
\hline 4 & 4 & 4 & 4 & 4 & 4 & 4 & 4 & 4 & 4 & 4 & 4 & 4 & 4 & 4 & 4 & 60 \\
\hline 5 & 4 & 3 & 3 & 4 & 4 & 3 & 3 & 3 & 3 & 4 & 3 & 4 & 3 & 4 & 4 & 52 \\
\hline 6 & 4 & 4 & 4 & 1 & 4 & 3 & 4 & 3 & 4 & 4 & 4 & 2 & 4 & 3 & 4 & 52 \\
\hline 7 & 4 & 2 & 4 & 4 & 4 & 3 & 4 & 4 & 4 & 4 & 4 & 4 & 4 & 4 & 3 & 56 \\
\hline 8 & 4 & 4 & 4 & 4 & 4 & 3 & 4 & 3 & 4 & 4 & 4 & 4 & 4 & 4 & 4 & 58 \\
\hline 9 & 4 & 2 & 4 & 4 & 4 & 3 & 4 & 4 & 4 & 4 & 4 & 4 & 4 & 1 & 4 & 54 \\
\hline 10 & 4 & 4 & 4 & 4 & 4 & 2 & 3 & 4 & 4 & 4 & 3 & 4 & 3 & 3 & 4 & 54 \\
\hline 11 & 4 & 4 & 4 & 4 & 4 & 4 & 4 & 4 & 4 & 4 & 4 & 4 & 4 & 4 & 4 & 60 \\
\hline 12 & 4 & 4 & 4 & 3 & 4 & 3 & 4 & 3 & 4 & 4 & 4 & 4 & 4 & 3 & 4 & 56 \\
\hline 13 & 4 & 4 & 4 & 4 & 4 & 4 & 3 & 4 & 3 & 3 & 4 & 4 & 3 & 4 & 4 & 56 \\
\hline 14 & 4 & 4 & 4 & 4 & 4 & 3 & 3 & 4 & 3 & 4 & 3 & 4 & 3 & 3 & 4 & 54 \\
\hline 15 & 4 & 4 & 4 & 4 & 4 & 4 & 4 & 4 & 4 & 4 & 4 & 4 & 4 & 4 & 4 & 60 \\
\hline 16 & 4 & 4 & 4 & 3 & 4 & 3 & 3 & 3 & 3 & 4 & 4 & 4 & 4 & 4 & 4 & 55 \\
\hline 17 & 4 & 3 & 3 & 4 & 4 & 4 & 3 & 4 & 2 & 4 & 4 & 4 & 4 & 3 & 4 & 54 \\
\hline 18 & 4 & 3 & 3 & 2 & 4 & 2 & 4 & 4 & 4 & 3 & 3 & 4 & 3 & 3 & 4 & 50 \\
\hline 19 & 4 & 4 & 3 & 3 & 4 & 2 & 3 & 2 & 4 & 4 & 3 & 4 & 3 & 3 & 4 & 50 \\
\hline 20 & 4 & 4 & 4 & 4 & 4 & 3 & 3 & 4 & 3 & 4 & 4 & 4 & 3 & 4 & 3 & 55 \\
\hline 21 & 4 & 3 & 3 & 3 & 3 & 3 & 3 & 3 & 2 & 4 & 4 & 4 & 3 & 4 & 4 & 50 \\
\hline 22 & 4 & 4 & 4 & 4 & 4 & 4 & 4 & 4 & 4 & 4 & 4 & 4 & 3 & 4 & 4 & 59 \\
\hline 23 & 4 & 4 & 4 & 4 & 4 & 4 & 4 & 4 & 4 & 4 & 4 & 4 & 4 & 4 & 4 & 60 \\
\hline 24 & 4 & 4 & 4 & 4 & 4 & 2 & 3 & 3 & 3 & 4 & 4 & 3 & 3 & 3 & 3 & 51 \\
\hline 25 & 4 & 4 & 4 & 4 & 4 & 3 & 2 & 3 & 3 & 4 & 4 & 4 & 4 & 4 & 4 & 55 \\
\hline 26 & 4 & 4 & 4 & 4 & 4 & 4 & 4 & 4 & 3 & 4 & 4 & 4 & 4 & 4 & 4 & 59 \\
\hline 27 & 4 & 4 & 4 & 4 & 4 & 4 & 4 & 4 & 4 & 4 & 4 & 4 & 4 & 4 & 4 & 60 \\
\hline
\end{tabular}


Thorigotuna | Jurnal Pendidikan Islam

\begin{tabular}{|l|l|l|l|l|l|l|l|l|l|l|l|l|l|l|l|l|}
\hline 28 & 4 & 4 & 4 & 4 & 3 & 4 & 4 & 4 & 3 & 4 & 4 & 4 & 4 & 4 & 4 & 58 \\
\hline 29 & 4 & 4 & 4 & 4 & 4 & 4 & 4 & 4 & 3 & 4 & 4 & 4 & 4 & 4 & 4 & 59 \\
\hline 30 & 4 & 4 & 4 & 4 & 4 & 4 & 4 & 4 & 4 & 3 & 4 & 4 & 4 & 4 & 4 & 59 \\
\hline 31 & 4 & 4 & 4 & 4 & 4 & 3 & 3 & 4 & 3 & 4 & 4 & 4 & 4 & 4 & 4 & 57 \\
\hline 32 & 4 & 4 & 4 & 4 & 4 & 2 & 3 & 4 & 3 & 4 & 4 & 4 & 4 & 4 & 4 & 56 \\
\hline
\end{tabular}

Berdasarkan skala penafsiran tersebut maka rata-rata variabel 59 berada pada interval diantara 57,8 - 60,77 dengan klasifikasi cukup. Hal ini menunjukan bahwa religiusitas peserta didik di sekolah MA Serba Bakti Suryalaya tergolong cukup.

\section{Analisis Kecerdasan Emosional peserta didik}

\section{Tabel 2}

Rekapitulasi nilai angket variabel Y

\begin{tabular}{|c|c|c|c|c|c|c|c|c|c|c|c|c|c|c|c|c|}
\hline \multirow{3}{*}{$\begin{array}{c}\mathrm{N} \\
\mathbf{0}\end{array}$} & \multicolumn{15}{|c|}{ Soal Angket } & \multirow{3}{*}{ Jumlah } \\
\hline & & & & & & & & & & 1 & 1 & 1 & 1 & 1 & 1 & \\
\hline & 1 & 2 & 3 & 4 & 5 & 6 & 7 & 8 & 9 & 0 & 1 & 2 & 3 & 4 & 5 & \\
\hline 1 & 2 & 4 & 4 & 4 & 4 & 4 & 3 & 3 & 3 & 4 & 3 & 2 & 4 & 3 & 4 & 51 \\
\hline 2 & 3 & 4 & 4 & 4 & 4 & 2 & 4 & 3 & 3 & 4 & 4 & 3 & 4 & 4 & 4 & 54 \\
\hline 3 & 4 & 4 & 4 & 4 & 4 & 3 & 4 & 4 & 3 & 4 & 4 & 4 & 4 & 3 & 4 & 57 \\
\hline 4 & 4 & 4 & 4 & 4 & 4 & 4 & 4 & 3 & 4 & 4 & 4 & 4 & 3 & 4 & 4 & 58 \\
\hline 5 & 3 & 4 & 4 & 4 & 4 & 4 & 4 & 3 & 4 & 4 & 4 & 3 & 4 & 4 & 3 & 56 \\
\hline 6 & 4 & 4 & 4 & 4 & 3 & 4 & 4 & 3 & 4 & 4 & 3 & 4 & 3 & 4 & 4 & 56 \\
\hline 7 & 3 & 4 & 4 & 4 & 3 & 4 & 4 & 4 & 4 & 4 & 4 & 4 & 2 & 3 & 4 & 55 \\
\hline 8 & 4 & 4 & 3 & 3 & 3 & 4 & 4 & 2 & 3 & 3 & 3 & 4 & 2 & 4 & 3 & 49 \\
\hline 9 & 4 & 4 & 3 & 4 & 4 & 3 & 4 & 3 & 3 & 4 & 3 & 4 & 4 & 3 & 4 & 54 \\
\hline 10 & 4 & 4 & 3 & 3 & 3 & 4 & 3 & 4 & 4 & 4 & 3 & 3 & 4 & 4 & 3 & 53 \\
\hline 11 & 4 & 4 & 4 & 4 & 4 & 4 & 4 & 3 & 3 & 4 & 4 & 4 & 4 & 4 & 4 & 58 \\
\hline 12 & 3 & 3 & 4 & 4 & 4 & 4 & 2 & 3 & 4 & 4 & 4 & 4 & 4 & 4 & 4 & 55 \\
\hline 13 & 4 & 4 & 4 & 4 & 4 & 4 & 4 & 2 & 3 & 4 & 4 & 3 & 4 & 4 & 2 & 54 \\
\hline 14 & 3 & 4 & 4 & 3 & 3 & 3 & 4 & 3 & 3 & 4 & 4 & 4 & 4 & 3 & 3 & 52 \\
\hline 15 & 3 & 4 & 4 & 4 & 4 & 4 & 4 & 4 & 4 & 4 & 4 & 4 & 4 & 4 & 4 & 59 \\
\hline 16 & 4 & 3 & 3 & 3 & 4 & 3 & 4 & 2 & 4 & 4 & 3 & 4 & 3 & 3 & 3 & 50 \\
\hline 17 & 4 & 4 & 4 & 4 & 4 & 2 & 4 & 3 & 2 & 4 & 4 & 4 & 3 & 4 & 4 & 54 \\
\hline 18 & 4 & 4 & 4 & 4 & 4 & 3 & 4 & 4 & 3 & 4 & 4 & 4 & 4 & 3 & 4 & 57 \\
\hline 19 & 4 & 4 & 4 & 4 & 4 & 3 & 4 & 4 & 3 & 4 & 4 & 4 & 4 & 2 & 4 & 56 \\
\hline 20 & 4 & 4 & 4 & 4 & 4 & 4 & 4 & 3 & 4 & 4 & 4 & 4 & 3 & 4 & 4 & 58 \\
\hline 21 & 4 & 3 & 3 & 3 & 4 & 4 & 3 & 4 & 3 & 4 & 3 & 4 & 4 & 4 & 4 & 54 \\
\hline
\end{tabular}


Sahliah, Siti Hanipah | Metode Pendidikan Inabah...

\begin{tabular}{|l|l|l|l|l|l|l|l|l|l|l|l|l|l|l|l|l|}
\hline 22 & 4 & 4 & 4 & 2 & 4 & 3 & 4 & 4 & 3 & 4 & 4 & 4 & 4 & 4 & 4 & 56 \\
\hline 23 & 4 & 4 & 4 & 4 & 4 & 4 & 4 & 4 & 3 & 4 & 4 & 4 & 4 & 4 & 4 & 59 \\
\hline 24 & 3 & 3 & 3 & 3 & 3 & 3 & 4 & 4 & 3 & 4 & 4 & 4 & 4 & 4 & 3 & 52 \\
\hline 25 & 4 & 4 & 4 & 3 & 4 & 4 & 4 & 4 & 3 & 3 & 4 & 4 & 4 & 4 & 3 & 56 \\
\hline 26 & 3 & 4 & 4 & 4 & 4 & 4 & 4 & 3 & 3 & 4 & 4 & 4 & 4 & 3 & 4 & 56 \\
\hline 27 & 4 & 4 & 4 & 4 & 4 & 4 & 4 & 4 & 3 & 4 & 4 & 4 & 4 & 4 & 4 & 59 \\
\hline 28 & 4 & 4 & 4 & 4 & 4 & 4 & 4 & 4 & 3 & 4 & 4 & 4 & 4 & 4 & 4 & 59 \\
\hline 29 & 4 & 4 & 4 & 2 & 4 & 3 & 4 & 3 & 3 & 4 & 4 & 3 & 4 & 4 & 4 & 54 \\
\hline 30 & 4 & 4 & 3 & 4 & 3 & 2 & 3 & 3 & 3 & 4 & 4 & 4 & 2 & 4 & 2 & 49 \\
\hline 31 & 4 & 4 & 4 & 4 & 4 & 4 & 4 & 4 & 3 & 4 & 4 & 4 & 4 & 3 & 4 & 58 \\
\hline 32 & 4 & 4 & 4 & 4 & 4 & 4 & 4 & 4 & 3 & 4 & 4 & 4 & 4 & 4 & 4 & 59 \\
\hline
\end{tabular}

Berdasarkan skala penafsiran tersebut maka rata-rata variabel 55,86 berada pada interval diantara 53,76 - 56,14 dengan klasifikasi cukup. Hal ini menunjukan bahwa kecerdasan emosional peserta didik di sekolah MA Serba Bakti Suryalaya tergolong cukup.

3. Analisis pengaruh Religiusitas terhadap kecerdasan emosional peserta didik

a. Menentukan ranking data variabel $\mathrm{X}$ dan variabel $\mathrm{Y}$

1) Meranking data variabel $X$

Tabel 3

Ranking variabel $\mathrm{X}$

$\begin{array}{ccccccccc}\text { Susunan } & 50 & 50 & 50 & 51 & 51 & 52 & 52 & 54 \\ \text { Posisi } & 1 & 2 & 3 & 4 & 5 & 6 & 7 & 8 \\ \text { Ranking } & 1,3 & 1,3 & 1,3 & 4,5 & 4,5 & 6,5 & \mathbf{6 , 5} & \mathbf{8 , 2} \\ & 54 & 54 & 54 & 54 & 55 & 55 & 55 & 56 \\ & 9 & 10 & 11 & 12 & 13 & 14 & 15 & 16 \\ & \mathbf{8 , 2} & \mathbf{8 , 2} & \mathbf{8 , 2} & \mathbf{8 , 2} & \mathbf{1 3 , 3} & \mathbf{1 3 , 3} & \mathbf{1 3 , 3} & \mathbf{1 6 , 2 5} \\ & 56 & 56 & 56 & 57 & 58 & 58 & 58 & 59 \\ & 17 & 18 & 19 & 20 & 21 & 22 & 23 & 24 \\ & 16,25 & 16,25 & 16,25 & 20 & 21,3 & 21,3 & 21,3 & 24,25 \\ & 59 & 59 & 59 & 60 & 60 & 60 & 60 & 60 \\ & 25 & 26 & 27 & 28 & 29 & 30 & 31 & 32 \\ & 24,25 & 24,25 & 24,25 & 28,2 & 28,2 & 28,2 & 28,2 & 28,2\end{array}$

2) Meranking Data Variabel $Y$

Tabel 4

Ranking data variabel $\mathrm{Y}$

$\begin{array}{lllllllll}\text { Susunan } & 49 & 50 & 51 & 52 & 53 & 53 & 54 & 54\end{array}$ 
Thorigotuna | Jurnal Pendidikan Islam

$\begin{array}{ccccccccc}\text { Posisi } & 1 & 2 & 3 & 4 & 5 & 6 & 7 & 8 \\ \text { Ranking } & 1 & 2 & 3 & 4 & 5,5 & 5,5 & 7,25 & 7,25 \\ & 54 & 54 & 55 & 55 & 55 & 56 & 56 & 56 \\ & 9 & 10 & 11 & 12 & 13 & 14 & 15 & 16 \\ & 7,25 & 7,25 & 11,3 & 11,3 & 11,3 & 14,3 & 14,3 & 14,3 \\ & 57 & 57 & 57 & 57 & 57 & 58 & 58 & 58 \\ & 17 & 18 & 19 & 20 & 21 & 22 & 23 & 24 \\ & 17,2 & 17,2 & 17,2 & 17,2 & 17,2 & 22,2 & 22,2 & 22,2 \\ & 58 & 58 & 59 & 59 & 60 & 60 & 60 & 60 \\ & 25 & 26 & 27 & 28 & 29 & 30 & 31 & 32 \\ & 22,2 & 22,2 & 27,5 & 27,5 & 29,25 & 29,25 & 29,25 & 29,2 \\ & & & & & & & & 5\end{array}$

Tabel 5

Menghitung Korelasi Rank Spearman Variabel X dan Variabel Y

\begin{tabular}{|c|c|c|c|c|c|c|}
\hline \multirow{2}{*}{ Jo } & \multicolumn{2}{|c|}{ Skor } & \multicolumn{2}{|c|}{ Ranking } & \multirow[t]{2}{*}{ Di } & \multirow[t]{2}{*}{$\mathrm{di}^{2}$} \\
\hline & $\mathrm{X}$ & Y & 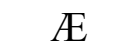 & Y & & \\
\hline 1 & 51 & 51 & 4,5 & 3 & 1,5 & 2,25 \\
\hline 2 & 58 & 54 & 21,3 & 7,25 & 14,05 & 197,4 \\
\hline 3 & 54 & 57 & 8,2 & 17,2 & -9 & 81 \\
\hline 4 & 60 & 58 & 28,2 & 22,2 & 6 & 36 \\
\hline 5 & 52 & 56 & 6,5 & 14,3 & $-7,8$ & 60,84 \\
\hline 6 & 52 & 56 & 6,5 & 14,3 & $-7,8$ & 60,84 \\
\hline 7 & 56 & 55 & 16,25 & 11,3 & 4,95 & 24,5 \\
\hline 8 & 58 & 49 & 21,3 & 1 & 20,3 & 412,09 \\
\hline 9 & 54 & 54 & 8,2 & 7,25 & 0,95 & 0,9 \\
\hline 10 & 54 & 53 & 8,2 & 5,5 & 2,7 & 7,29 \\
\hline 11 & 60 & 58 & 28,2 & 22,2 & 6 & 36 \\
\hline 12 & 56 & 55 & 16,25 & 11,3 & 4,95 & 24,5 \\
\hline 13 & 56 & 54 & 16,25 & 7,25 & 9 & 81 \\
\hline 14 & 54 & 52 & 8,2 & 4 & 4,2 & 17,64 \\
\hline 15 & 60 & 59 & 28,2 & 27,5 & 0,7 & 8,95 \\
\hline 16 & 55 & 50 & 13,3 & 2 & 11,3 & 127,69 \\
\hline 17 & 54 & 54 & 8,2 & 7,25 & 0,95 & 0,9 \\
\hline 18 & 50 & 57 & 1,3 & 17,2 & $-15,9$ & 252,81 \\
\hline 19 & 50 & 56 & 1,3 & 14,3 & -13 & 169 \\
\hline 20 & 55 & 58 & 13,3 & 22,2 & $-8,9$ & 79,21 \\
\hline 21 & 50 & 54 & 1,3 & 11,3 & -10 & 100 \\
\hline 22 & 59 & 56 & 24,25 & 17,2 & 7,05 & 49,7 \\
\hline
\end{tabular}


Sahliah. Siti Hanipah | Metode Pendidikan Inabah...

$\begin{array}{lllcccc}23 & 60 & 59 & 28,2 & 29,25 & -1,05 & 1,1 \\ 24 & 51 & 52 & 4,5 & 5,5 & -1 & 1 \\ 25 & 55 & 56 & 13,3 & 17,2 & -3,9 & 15,21 \\ 26 & 59 & 56 & 24,25 & 17,2 & 7,05 & 49,7 \\ 27 & 60 & 59 & 28,2 & 29,25 & -1,05 & 1,1 \\ 28 & 58 & 59 & 21,3 & 29,25 & -7,95 & 63,2 \\ 29 & 59 & 54 & 24,25 & 22,2 & 2,05 & 4,2 \\ 30 & 59 & 49 & 24,25 & 22,2 & 2,05 & 4,2 \\ 31 & 57 & 58 & 20 & 27,5 & -7,5 & 56,25 \\ 32 & 56 & 59 & 16,25 & 29,25 & -13 & 169\end{array}$

1) Menghitung korelasi antara variabel $X$ dengan variabel $Y$ dengan menggunakan rumus rank spearman (rs), dengan rumus:

$$
\begin{aligned}
\text { rs } & =1-\frac{6 \sum d i^{2}}{N^{3}-N} \\
\text { rs } & =1-\frac{6(2179,47)}{32^{3}-32} \\
& =1-\frac{22909,86}{32768-32} \\
& =1-\frac{22909,86}{32736} \\
& =1-0,40 \\
\mathrm{rs} & =0,60
\end{aligned}
$$

2) Menginterpretasikan nilai rs pada skala Guildford:

$0,00-0,20 \longrightarrow$ Very low (Sangat Rendah)

$0,21-0,40 \longrightarrow$ Low (Rendah)

0,41-0,60 $\longrightarrow$ Moderate (Cukup)

$0,61-0,80 \longrightarrow H i g h$ (Tinggi)

0,81-1,00 $\longrightarrow$ Very high (Sangat Tinggi)

Berdasarkan angka korelasi 0,60 dalam skala kualifikasi Guilford berada pada interval 0,41 - 0,60 dengan klasifikasi cukup. Artinya adanya pengaruh yang cukup antara religiusitas terhadap kecerdasan emosional peserta didik di MA Serba Bakti Suryalaya.

3) Menghitung derajat determinasi 
Untuk mengetahui $\mathrm{C}$ derajat keterpengaruhan karakter peserta didik oleh budaya religius dihitung koefisien determinasi dengan rumus:

$$
\begin{aligned}
\mathrm{D} & =\mathrm{rs}^{2} \times 100 \% \\
& =0,6^{2} \times 100 \% \\
& =0,36 \times 100 \% \\
\mathrm{D} & =36 \%
\end{aligned}
$$

Hasil perhitungan di atas menunjukkan bahwa kecerdasan emosional peserta didik di MA Sserba Bakti Suryalaya terkena pengaruh oleh religiusitas sebesar $36 \%$. Sedangkan faktor lain mencapai $64 \%$. Hal ini menunjukkan bahwa masih ada faktor-faktor lain yang bisa mempengaruhi kecerdasan emosional peserta didik di MA Serba Bakti Suryalaya

4) Signifikasi atau uji hipotesis dengan rumus

Pengujian hipotesis ini menghasilkan sebuah kesimpulan untuk menerima atau menolak hipotesis yang di ajukan. Maka, untuk menguji hipotesis ini digunakan rumus sebagai berikut:

$t_{\text {hitung }} r_{s} \frac{\sqrt{N-2}}{1-r s^{2}}$

Mencari derajat kebebasan dengan rumus:

$\mathrm{Dk}=(\mathrm{n}-2)$

Sehingga pengujian hipotesis dengan ketentuan sebagai berikut:

a.Jika $t_{\text {hitung }} \geq t_{\text {tabel }}$ maka Ha diterima dan Ho ditolak

b.Jika $t_{\text {hitung }} \leq t_{\text {tabel }}$ maka Ha ditolak dan Ho diterima

$$
\begin{aligned}
& t_{\text {hitung }} r_{s} \sqrt{\frac{N-2}{1-r_{s}^{2}}} \\
& t_{\text {hitung }}=0,6 \sqrt{\frac{32-2}{1-0,6^{2}}} \\
& t_{\text {hitung }}=0,6 \sqrt{\frac{30}{1-0,36}}
\end{aligned}
$$




$$
\begin{aligned}
& t_{\text {hitung }}=0,6 \sqrt{\frac{30}{0,64}} \\
& t_{\text {hitung }}=0,6 \sqrt{46,88} \\
& t_{\text {hitung }}=0,6 \cdot 6,85 \\
& t_{\text {hitung }}=4,11
\end{aligned}
$$

Selanjutnya menghitung $\mathrm{t}_{\text {tabel }}$

$$
\begin{aligned}
& t_{\text {tabel }}=t(1-a)(d k) \\
& t_{\text {tabel }}=t(1-a)(n-2) \\
& t_{\text {tabel }}=t(1-0,05)(32-2) \\
& t_{\text {tabel }}=t(0,95)(30) \\
& t_{\text {tabel }}=2,042
\end{aligned}
$$

Maka hasil dari penelitian ternyata $t_{\text {hitung }}$ sebesar 4,11 sedangkan $t_{\text {tabel }}$ sebesar 2.042 jadi dapat dijelaskan bahwa $t_{\text {hitung }} 4.11 \geq t_{\text {tabel }} 2,042$ sehingga Ha diterima dan Ho ditolak. Setelah uji signifikasi korelasi antara “ pengaruh religiusitas terhadap kecerdasan emosional peserta didik di MA Serba Bakti Suryalaya “.

\section{Pembahasan}

Hasil dari deskripsi penelitian dan hasil analisis data dapat dijabarkan sebagai berikut:

1. Pengaruh religiusitas tergolong cukup. Hal ini berdasarkan pada hasil penelitian yang dilakukan kepada 32 responden dengan menggunakan angket, kemudian dihitung skala penafsirannya dengan memperoleh rata-rata sebesar 59 yang berada pada interval diantara 57,18 - 60,77 dengan klasifikasi cukup.

2. Kecerdasan emosional peserta didik di MA serba bakti suryalaya tergolong cukup, hal ini berdasarkan pada hasil penelitian yang dilakukan kepada 32 responden dengan menggunakan angket, kemudian dihitung skala penafsirannya dengan memperoleh 
rata-rata sebesar 55,86 yang berada pada interval diantara 53,76 - 56,14 dengan klasifikasi cukup.

3. Religiusitas di sekolah MA Serba Bakti Suryalaya memberikan dampak yang positif terhadap kecerdasan emosional peserta didik. Hal ini berdasarkan perhitungan korelasi antara variabel (X) dengan variabel (Y) yang menggunakan rumus rank spearman (rs), dengan harga rs sebesar 0,60 Angka korelasi rank spearman tersebut berada pada interval 0,41 - 0,60 dengan kualifikasi cukup . Artinya adanya pengaruh yang cukup antara religiusitas di sekolah terhadap kecerdasan emosional peserta didik di sekolah tersebut. Melalui uji hipotesis diketahui bahwa angka korelasi tersebut signifikan. Sebab terbukti $t_{\text {hitung }} 4,11$ lebih besar daripada $t_{\text {tabel }} 2,042$. Dengan demikian disimpulkan bahwa hipotesis alternatif (Ha) yang menyatakan adanya pengaruh positif antara kedua variabel tersebut diterima. Lalu hasil hitung koefisien determinasi diketahui terdapat pengaruh sebesar 36\%, selebihnya dipengaruhi oleh faktor lain, yakni sebesar $64 \%$. Dengan demikian, ternyata masih banyak faktor yang mempengaruhi kecerdasan emosional peserta didik.

\section{SIMPULAN}

Berdasarkan hasil analisis dan pembahasan, maka dapat disimpulkan bahwa setelah diuji signifikansi korelasi antara religiusitas dengan kecerdasan emosional peserta didik di MA Serba Bakti Suryalaya ada pengaruh yang positif dan signifikan.

Berdasarkan kesimpulan, adapun saran yang dapat penulis sampaikan adalah sebagai berikut :

1. Bagi peserta didik

Peserta didik hendaknya lebih meningkatkan religiusitas, karena hal tersebut dapat mendukung terbentuknya kecerdasan emosional yang lebih baik. 
2. Bagi sekolah

Pihak sekolah perlu mempertahankan budaya keagamaan yang sudah baik dan menambahkan kembali kegiatan yang berhubungan dengan keagamaan supaya dapat membantu dalam meningkatkan religiusitas peserta didik.

3. Bagi guru

Guru diharapkan mencontohkan hal-hal yang baik agar peserta didik dapat meniru segala tingakh laku dan ucapan dengan baik.

4. Bagi Orang tua

Orang tua senantiasa memperhatikan aspek religiusitas khususnya remaja, karena pada masa perkembangan remaja dikenal dengan proses pencarian jati diri sehingga apapun yang membuat penasaran akan dicoba dan badai emosi sulit dikontrol dengan baik sehingga membutuhkan perhatian khusus supaya terhidar dari pengaruh emosi negatif.

\section{DAFTAR PUSTAKA}

Abah Anom. (1983). Akhlakul Karimah Akhlakul Mahmudah. Tasikmalaya: Yayasan Pondok Pesantren Suryalaya.

Alba, Cecep. (2012). Tasawuf dan Tarekat. Bandung : Remaja Rosdakarya.

Ali, Muhammad \& Muhammad Asrori. (2015). Psikologi Remaja : Perkembangan Peserta Didik. Jakarta : Bumi Aksara.

Ancok, Djamaludin dan Fuad Nashori Suroso. (2011). Psikologi Islam Solusi Islam Atas Problem-Problem Psikologi. Yogyakarta: Pustaka Pelajar.

Arikunto,Suharsimi. (2010). Prosedur Penelitian. Jakarta : Rineka Cipta.

Daradjat, Zakiah. (1996). Ilmu Jiwa Agama. Jakarta : Bulan Bintang. Djaali. (2006). Psikologi Pendidikan. Jakarta: Bumi Aksara.

Efendi, Agus. (2005). Revolusi Kecerdasan Abad 21. Bandung : Alfabeta. 
Ginanjar, Ary. (2005). Rahasia Sukses Membangun Kecerdasan Emosi dan Spiritual ESQ (Emotional Spiritual Quotient). Jakarta : Arga.

Goleman, Daniel. (2003). Working With Emotional Intelligence : Kecerdasan Emosi untuk Mencapai Puncak Prestasi. Terjemahan Alex Tri Kantjono Cet. V. Jakarta : PT. Gramedia. . (2007). Emotional Intelligence. Terjemahan T Hermaya Cet. XVII. Jakarta: PT. Gramedia Pustaka Utama. . (2015). Emotional Intelligence : Mengapa EI Lebih Penting daripada IQ. Terjemahan T Hermaya Cet. XX. Jakarta : Gramedia Pustaka Utama.

Istadi, Irawati. (2006). Melipatgandakan Kecerdasan Emosi Anak. Bekasi: Pustaka Inti.

Jalaluddin. (2009). Fikih Remaja. Jakarta : Kalam Mulia.

Jalaluddin. (2015). Psikologi Agama : Memahami Perilaku dengan Mengaplikasikan Prinsip-prinsip Psikologi. Jakarta : Raja Grafindo persada.

Muhaimin. (2012). Paradigma Pendidikan Islam. Bandung : PT. Remaja Rosdakarya.

Mustaqim. (2001). Psikologi Pendidikan. Yogyakarta: Pustaka Pelajar Offset.

Nashori, Suroso dan Mucharam. (2002). Mengemangkan Kreativitas Dalam Perspektif Psikologi Islam. Yogyakarta : Menara Kudus.

Nasution, Harun. (2008). Islam Ditinjau dari Berbagai Aspek. Jakarta : Universitas Indonesia.

Sarwono, Sarlito Wirawan. (2013). Pengantar Umum Psikologi. Jakarta: Rajawali Pers.

Shihab, M. Quraish. (1994). Membumikan Al-Qur'an. Bandung : Mizan. Shihab, M. Quraish. (2002). Tafsir Al Misbah Kesan dan Keserasian Al-Quran vol.1. Jakarta : Lentera Hati.

Sobur, Alex. (2016). Psikologi Umum. Bandung : Pustaka Setia.

Sugiono, Dendy. (2008). Kamus Besar Bahasa Indonesia Pusat Bahasa Edisi Keempat. Jakarta : PT. Gramedia Utama.

Sugiyono. (2017). Metode Penelitian Pendidikan. Bandung : Alfabeta. 
Sahliah, Siti Hanipah I Metode Pendidikan Inabah...

Sutoyo, Anwar. (2009). Bimbingan dan Konseling Islami Teori \& Praktik. Semarang: CV. Widya Karya Semarang.

Wawan. Pengantar Statistika Pendidikan. Tasikmalaya : CV. Latifah.

Yusuf, Syamsu. (2012). Psikologi Perkembangan Anak dan Remaja.

Bandung : PT Remaja Rosdakarya. 